\title{
Research on Animation Elements in Packaging Design
}

\author{
Wen Lilei \\ School of Design Art, Xijing University, Xi’an, Shaanxi Province, China, 710123
}

Keywords: packaging design; animation elements; advantages; strategies; research

\begin{abstract}
Century, China has entered the information age. In this era of big data and information, all kinds of information are coming. Our pace of life is faster and faster. Various kinds of packaging design products we see are multifarious and dazzling, which makes consumers feel an aesthetic fatigue. Animation elements have very distinctive features, which can be used in packaging design to show the goods are different, unique, but also to stimulate consumer desire to buy. This paper expounds the advantages of applying animation elements to packaging design, and focuses on the specific strategies of applying animation elements to packaging design, in order to improve the level of commodity packaging design.
\end{abstract}

\section{Introduction}

With the deep implementation of the socialist market economy in China, the market competition is becoming more and more intense, and the consumers' choice of goods has also raised a higher level of demand. At present, most consumers not only consider the quality and brand, but also pay more attention to the packaging design of goods. In this case, how to design to stimulate the desire to buy consumers has become the focus of business considerations. The application of animation elements in packaging design provides an innovative idea for the designer. Especially in recent years, the animation hot, such as Tang Laoya, Mickey Mouse, vigorously seaman animation is known to every family Beaming with Joy etc. This article is to explore how to apply animation elements in the packaging design [1].

\section{Advantages of animation elements in packaging design}

In life, snacks become one of our necessities. Especially for children and young people, snacks are their favorite food. In the eyes of children, they have higher requirements for the packaging design of goods, they like the strange shape, Xian Yanduo purpose packaging design. At this point, they even exceed the brand and taste requirements. At the same time, children see the most animated cartoon every day, playing the most is a variety of toys. They can all kinds of cartoon characters recite, so every time parents accompany them into shopping malls, love animation has become their first choice to see, buy goods. When Beaming with Joy and grey wolf when China is hot, it is not difficult to find all kinds of dolls, drinks and puffed food in security design are joined the animation elements, and good economic benefit is obtained. In addition to children, young people are very fond of animation elements. In today's fast-paced society, young people's life pressure is very large. After a day's running for life, eating snacks and watching TV plays a way to relax their stress. The easy, lovely and funny animation can remind them of the simple days of their childhood. As a result, the application of animation elements to the design of commodity packaging also conforms to the consumption needs of young people [2].

At present, due to the prosperity and development of the market economy, a variety of similar products, the quality of goods on the performance of the difference is not big. But some businesses can become the leader of the same type of goods sales, because these businesses can more accurately understand the needs of consumers, and then in the first time to grasp the market opportunities. Among contemporary society people more profound sense of distance, the sense of trust is low, all kinds of goods in large numbers, and the application of animation elements in the packaging design of merchandise, is more like a familiar old friend, see if they remembered the day 
once the most happy, the animation is always accompany us to grow up. But in the memory seems never fade. Merchants apply animated elements to packaging design, and arouse people's inner feelings. When people buy goods, they will naturally choose these packaging design products with animation elements [3].

Everyone is different, and everyone's aesthetic level is also different. But the common point is that people are most likely to accept what they are familiar with. Many businesses have tried to create a unique brand in the packaging design, but in this process, not only increased the cost, but also spent a long time to come and let people accept and identify. But if animated elements are used, the problem is avoided. Each cartoon character has a story background, and each animation character has a certain personal image. In the process of application, businesses do not need to waste much time to set up images for animated characters, but simply enjoy the good maintenance, design and apply them to get consumers' love [4].

\section{The application characteristics of animation elements in packaging design}

In modern society, packaging can not only disseminate commercial information, but also embody fashion culture. That is to say, from the packaging design of goods, we can find out the development message and fashion trend of an era. And as for the mastery of these fashion information, it can be able to keep up with the development of the trend of the times, and can meet the aesthetic needs of consumers. Animation itself belongs to the product of fashion, coupled with young people are very unconventional, the pursuit of fashion, the use of animation elements in the packaging design of goods, more able to meet the consumer's inner needs. For the business, whether it is a new cartoon image created for its own goods, or the classic cartoon image, it embodies a certain fashion. In recent years, China's animation industry development is relatively fast, especially in the support of new media, animation image is deeply rooted in the hearts of the people, become synonymous with fashion. For example, duo A dream series, Kitty cat series, etc., is becoming a favorite cartoon character of thousands of girls. These elements can be applied to the design of commodity packaging, which can promote the sale of goods and promote the development of the market [5].

Animated images are generally exaggerated and funny. Most of these animation images come from people's lives, and they appear in the public view after exaggeration and creation. They don't need to be expressed in words, and they can show some effect through simple and funny body movements. For example, we had a lot of fun before called cookies, in its advertisements is a few biscuits happy dancing and drive lens, let a person very impressive. This is a biscuit packaging design is very characteristic, the use of packaging bags and painted khaki, red lips on it. As long as you see this package, you can think of advertising, and then produce the desire to buy. It can be seen that animation elements have certain abstraction, and compared with other images, it is more humorous, humorous and lively, which can bring people boundless joy. From this point, we can not doubt that the animation image itself has this funny character, so the public will feel more interesting. This is also the reason why animated images are popular with children and young people [6].

Someone once said, successful animation image or mascot, should be able to draw the children out. And what I want to say is that even if the child can not draw it, it must be able to make children interested in the packaging design of goods, it is difficult to forget. We often say that art without borders, and good animation image must be able to cross cultural differences, geographical differences, professional differences, age differences, cultural differences, which is the animation image of the common. And the realization of animation image often requires the company to give certain story background to show the cultural connotation and significance of animation image in the process of commodity operation. For businesses, the customer as God exists, and businesses want to let the consumer remember products occupy a certain market share, which requires the animation elements businesses in the packaging design, when the application of simple, not only to impress, but also let people find everything fresh and new, stimulate consumer desire to buy, to create more benefits for the merchant. 
In daily life, we can consume to meet the needs of life, but also to show the culture. China is one of the four ancient civilizations. It has five thousand years of cultural history and is very profound. And through packaging design can also be reflected in this cultural connotation. For consumers, the ability to catch their eyes is not only the animated images designed by foreign countries, but also the image of China's animation can attract consumers' attention. Such as the Kung Fu Panda series, has been very popular. The panda is a national treasure in China, with its naive image by love people in china. In addition, with the Kung Fu Panda movie series and all kinds of panda products publicity, given the panda a certain connotation, it represents the spirit of Kung Fu, representing never give up, represents perseverance. The use of this animation element in commodity packaging design can not only stimulate consumers' desire to buy, but also spread our culture and realize the communication and dissemination between Chinese culture and world culture. And this way of spreading the culture is no doubt easy and imperceptible, and the impression it brings is very profound.

\section{The development prospect of animation elements in packaging design combination of the development trend of the times}

The world is changing every day, and the speed of change is hard to imagine. This requires designers to combine animation elements in packaging design with the trend of the times, constantly enrich and create animation images, so that they will not be eliminated by the times. Over the years, Coca-Cola has been one of the most popular drinks in the eyes of the public, because its designers will be based on the development trend of the times in the design, the use of the most fashionable elements, packaging re transformation. They are both in the packaging design application, lovely funny animated image and used familiar with warm, classic lines used in melody and lyrics, hook memories used a variety of heart warming stories, it is because it can make the appropriate changes according to the changes of the times, it has dominated the beverage sales the market has not been eliminated. Thus, in the packaging design, in addition to the application of animation image, but also conform to the trend of development of the times.

For goods, packaging is an important coat, consumer understanding of goods is often through external packaging to achieve. The application of color in the external packaging design can stimulate the visual of consumers, improve consumers' awareness of commodities, and stimulate consumers' desire to buy. When we observe an object, each of us is usually through the color, in the human visual elements, people's vision is the most sensitive, people's ability to color is the strongest. Basically, people observe objects, the observation of color should be more than eighty percent, the observation of the shape is only twenty percent. At the same time, in the contrast of color, bright and new combination of color is easy to attract people's attention. But monotonous, heavy color is difficult to attract people's eyes.

Especially in recent years, fashion color has become the pronoun of fashion every year. It adheres to the principle of innovation, attracting consumers' eyes and stimulating consumers' desire to buy. But for designers, only by mastering the basic color knowledge, and the reasonable collocation and application of color, can we design a kind of packaging to attract consumers' eyes.

As a business, in order to stimulate the inner feelings of consumers, so that they focus on merchandise, to fondle admiringly, must be a painstaking effort, to better shape design. Especially for the emotional type of food, in the food packaging we can use the emotional color, for example the use of pictures, has a unique style of romantic legends and literary hand-painted illustrations, creating an emotional atmosphere, so that consumers feel from the packaging of the emotion. When consumers receive this signal, they will have desire for food in the packaging, and then produce desire to buy. For example, the current snack packaging has been applied animation or hand-painted style, touched many girls heart, become the favorite girls. 


\section{Conclusion}

To sum up, through the analysis and research of this article, we understand the importance of applying animation elements to packaging design. For modern enterprises, in the process of application, we must realize that animation elements are no longer the accessories of packaging design, no longer simply a decorative pattern, it is a culture, but also a kind of power to highlight the value of enterprises. Therefore, the enterprise should combine the trend of the development of the times, apply the animation elements, design the commodity packaging that can stimulate the consumer's desire to buy.

\section{References}

[1] Xu S. Research on Application of National Elements in Animation Design[J]. 2015.

[2] $\mathrm{Xu} \mathrm{S}, \mathrm{Xu} \mathrm{S}, \mathrm{Xu} \mathrm{S}$, et al. Research on Application of National Elements in Animation Design[C]// - International Symposium on Social Science. 2015.

[3] Zhang M. Research on the Use of Traditional Cultural Elements in the Animation Design[J]. Journal of Hubei Correspondence University, 2015.

[4] Xiang Z, Zhang L. Research on interactive animation elements of interaction picture book based on children's cognition[C]// International Conference on Progress in Informatics and Computing. IEEE, 2014:246-249.

[5] Bailu, Jiang. Analysis of the Traditional Ethnic Elements Application in Animation Design[J]. Zhouyi Research, 2014:23-25.

[6] Yang Y, Yang H. The Animation Design of Fusible Material Based on Graphics[C]// Advanced Research on Electronic Commerce, Web Application, \& Communication, Communications in Computer \& Information Science, 143 Isbn-4 Springer Berlin Heidelberg, P. Springer Berlin Heidelberg, 2011:421-426. 